\title{
Augmented and Virtual Reality in Mobile Fitness Applications: A Survey
}

\author{
Ryan Alturki and Valerie Gay \\ Faculty of Engineering and Information Technology, University of Technology Sydney, \\ 15 Broadway, Ultimo NSW 2007, Australia \\ Ryan.M.Alturki@student.uts.edu.au, Valerie.Gay@uts.edu.au
}

\begin{abstract}
Obesity is a major issue around the world. It is a main reason for several chronic diseases. Obesity can be stopped by encouraging people to do physical activities and making behaviour intervention regarding life style. Mobile fitness apps are emerging because of the unique features that are provided. They are seen as a vital tool to motivate people suffering from obesity to perform physical activities and make behaviour intervention regarding health and fitness. Augmented reality (AR) and virtual reality (VR) technologies have been used successfully in different kinds of mobile apps. This paper presents a systematic review of some of the most recent AG and VR researches in mobile apps. It discusses the main findings of applying both technologies in different fields of mobile apps. Based on this systematic review, a mobile fitness mobile app for obese individuals that consider both AR and VR technology will be developed.
\end{abstract}

Keywords: Mobile Application, Fitness Application, Augmented Reality (AR), Virtual Reality (VR).

\section{Introduction}

Obesity is a major health problem around the world. Obesity can be defined as abnormal or excessive fat accumulation that may impair health [1]. Around the world, $15 \%$ of the current population are considered to be obese and almost $40 \%$ of the current population are suffering from overweight. [2]. Both obesity and overweight are seen as the main reason for several dangerous chronic diseases, for example, diabetes and hypertension [3] and [4]. As a result of this, several researchers were motivated to find a way to control and stop the spread of obesity [5], [6], [7] and [8]. The majority of researchers' results concluded that obesity could be controlled and stopped by doing physical exercises and changing eating happiest. Nevertheless, several experts believe that motivate people who are suffering from obesity to lose weight and have a better lifestyle is not easy. They believe that behaviour intervention is seen one of the best ways for changing behaviour that is related to fitness and health [9] and [10].

During the last few years the use of fitness mobile apps is becoming popular around the world and especially by people suffering from obesity and want to lose 
weight to have a better lifestyle. According to a recent study the international fitness technology market is estimated to be worth around 19 billion U.S dollars in 2014 [11]. According to a report undertaken by Nielsen's Mobile NetView, one-third (46 millions) of US smartphone owners use fitness mobile apps [12]. Around the world, $16 \%$ of all Internet users use health and fitness mobile apps [13]. In 2014, the mobile app business had expanded by $15 \%$ overall. Regarding average daily usage, the number of health and fitness apps increased by $62 \%$ [14].

Supporting health behaviour change via using mobile fitness and health apps is promising. The number of fitness and health apps have increased rapidly in the last few years and by today there are more than thirty-one thousand fitness and health apps available to use [15]. Moreover, the interest of how fitness' apps role can influence the behaviour of people who suffer from obesity is growing. A recent study introduced a framework that named "Functional Triad" which aims to describe the device's role in the device-human interaction [16]. The study explains that devices can act as tools, mediums and social actors for motivating human. For instance, mobile fitness apps can play the role of predisposing tools for diffusing fitness information. Furthermore, personal information regarding users' behaviour can be collected by them and can connect users to several social networks.

To influence the behaviour of obese individuals, mobile fitness apps should have unique features that play an important role in motivating obese individuals. A recent survey states that there are four main features motivates obese individuals to use mobile fitness apps in order to lose weight and have a better lifestyle. These features are [17]:

- Goal settings;

- Monitoring, tracking and feedback;

- Reminders and alerts;

- Rewards or gamification.

However, there are serval technologies that have emerged over the last year and had been used widely in mobile apps as a motivational tool, for example, augmented reality (AR) and virtual reality (VR). Pokemon Go is a mobile app game that uses AR technology as an entertainment tool. According to a recent report Pokemon Go has been downloaded 650 million times around the world [18].

This research seeks to contribute to significant researches concerning both AG and VR technologies in mobile apps. The aim of this study is to conduct a systematic review which reveals the most prominent and recent AG and VR studies in mobile apps that have been discussed and have emerged in the literature. This research is going to be useful for developing a mobile fitness app that considers both AG and VR technologies. This survey is unique because it discusses some of the most contemporary literature.

\section{The Systematic Review}

We undertook a systematic review to search for published, peer-reviewed articles that investigated AG and VR in mobile apps. We utilised the terminology outlined in the 
table below (Table 1) to look for research papers covering AG and VR in mobile devices and applications. We sought to incorporate all the related terms that could provide us with articles relevant to this topic.

We referred to JMIR, CINAHL, Academic Search Premier, PsycINFO, Health Source, Communication and Mass Media Complete, Computers and Applied Sciences Complete, Psychology and Behavioural Sciences Collection, Computer Source, PubMed, Web of Science and PsychARTICLES.

We have followed the methodology from [17] and the flow chart below shows how the systematic review was undertaken.

Table 1. Keywords used in the systematic review relating to AG and VR technologies in mobile applications

\begin{tabular}{|c|l|c|}
\hline Search Lines & Search terms & Filtered by \\
\hline Line 1 & $\begin{array}{c}\text { Mobile Device OR Mobile Phone OR Smart } \\
\text { Phone }\end{array}$ & Title/Abstract \\
\hline 2. AND & Applications OR Apps & Title/Abstract \\
\hline 3. AND & Fitness Applications OR Fitness Apps & Title/Abstract \\
\hline 4. AND & Augmented reality OR AR & Title/Abstract \\
\hline 5. AND & Virtual reality OR VR & Title/Abstract \\
\hline 6. AND & $\begin{array}{c}\text { Augmented reality in mobile applications OR } \\
\text { AR in mobile apps OR AR in apps }\end{array}$ & Title/Abstract \\
\hline 7. AND & $\begin{array}{c}\text { Virtual reality in mobile applications OR VR } \\
\text { in mobile apps OR VR in apps }\end{array}$ & Title/Abstract \\
\hline
\end{tabular}






Fig. 1. Methodology for the systematic review

\section{Results}

We conducted a systematic literature review of AR and VR in mobile apps. We looked for articles that discussed AR and VR in mobile devices and applications. We also conducted a comprehensive literature review on AR and VR in mobile apps and tried to figure out the important attributes discussed in these papers. 


\subsection{Augmented Reality in Mobile Apps}

In AR, physical reality can become enhanced through the additional information that computers can generate in real time [19]. Over the time, the definition of AR has been broadened and the following properties are believed to be part of any AR system [20]:

- AR systems combine virtual and real objects in a real environment;

- AR systems run in real time and interactively;

- AR systems align or register virtual and real objects with each other.

Milgram and Kishino introduced a continuum of real-to-virtual environments. In the continuum they showed AR as part of mixed reality. The surrounding environment in AR is always real unlike augmented virtuality and virtual environments [21]. AR has greatly improved over the last few decades and today AR usage is built into smartphone apps such as AR Travel Guide [22]. The concept of AR technology has been proven to have been effectively applied to mobile devices [23]. Rohs and Gfeller proposed the use of portable devices and smartphones rather than specialised hardware to build AR apps [24]. According to Hollerer and Feiner mobile AR is a combination of various components such as display technology, computational platform, global tracking technologies, data access technology, wireless communication and interaction technology [25].

There are many apps with AR features developed for various purposes. These features have been found to enhance the mobile applications' usability. There were different approaches discussed by to improve learnability of mobile apps [26]:

-Improving graphical icons characteristics that presence icon usability and concreteness;

-Introducing multi-layered interfaces to allow the users to adopt an improved mental framework and reduce complexity;

-Enhancing the mobile device's interface through the use of a larger display that allows for guidance and feedback in real time.

Augmented mobile apps better enable the use of mobile devices amongst those with declining cognitive ability such as the elderly [27]. Kim and Dey discovered that the use of AR in the windshield displays of vehicles help older people in cognitive mapping was very effective [28]. The findings showed a noticeable decrease in terms of distractions and errors in navigation when compared to earlier models of such windshield displays designed for the elderly. AR uses have also been discussed in the tourism sector. A research identified the benefits of using AR in tourism mobile apps through developing and evaluating a tourist mobile app with Augmented Reality. The results proved that AR enhances the tourist experience in an innovative way. Therefore, AR apps in different industries can improve the quality of service [29].

AR in mobile apps represents a great opportunity for better access to digital and print library collections. Mobile apps with AR technology deliver an interactive and engaging information experience. AR can help apps overlay graphical data and this makes apps with AR technology well-suited for engagement in both library and real world offsite interaction with the content. A research by introduces mobile AR apps for next-generation library services and uses [30]. They study shows that mobile AR 
apps can help augment browsing of physical book stacks, optical character recognition, facial recognition and library navigation. The paper suggests Mobile AR uses and apps in library settings as well as introducing a model to demonstrate a prototype interface.

\subsection{Virtual Reality in Mobile Apps}

VR is defined as a computer-simulated or immersive multimedia reality [31]. VR technology uses computers to replicate an imagined or real environment. It allows user interaction through simulating the user's physical environment and presence. VR can artificially create sensory experience, such as touch, sight smell, and hearing. The origins of VR came from the science fiction world. In 1935 Stanley G. Weinbaum's short story "Pygmalion's Spectacles"; it is considered as a pioneer work of fiction that introduces VR. The story describes a VR system operated via goggles which used holographic simulations to record users' fictional experiences and incorporated the senses of smell and touch [32]. Bob Sproull and Ivan Sutherland in 1968 created the first AR and VR Head- Mounted Display (HMD) system [33]. In 1978, MIT created the Aspen Movie Map that is one of the more famous hypermedia and virtual reality systems. This program was more of Aspen's virtual simulation. People could explore a town's streets in a 'polygon' mode as well as two others labelled 'winter' and 'summer'; two of these relied on photographs. The developers' purpose was to capture every possible journey through the city's network of roads and streets. The third mode was a 3-D model of the town [34]. Street View was then introduced by Google in 2007, it consists of panoramic views of numerous worldwide locations that include indoor buildings, roads and rural areas. In 2010, a stereoscopic mode was introduced [35]. Virtual reality is used then in many mobile apps in order to enhance UX.

Mobile apps related to health, education and gaming now increasingly have virtual reality features to increase the usability of the app. A research designed an educational game with virtual reality and the results demonstrated that the game was likeable and usable. The researchers, however, believed there was ample scope for improvement in likeability and usability to maximize educational benefits [36]. A study presented an environment in a demo that enabled users to explore different three-dimensional (3D) visualisations on tablets and smartphones [37]. A performance and feedback-based app was tested and compared to a gamed-based one with virtual reality [38]. The aim was to examine their effects on aspects of immediate response to an exercise bout. The participants reported the app with virtual reality had a more associative attentional focus.

VR offers a lot of useful apps for tourism and deserve greater attention from tourism professionals and researchers. A study shows that with the continuous evolution of VR technology, the significance and number of such apps will increase. Marketing, planning and management, entertainment, heritage preservation, education, and accessibility are some areas of tourism in which VR could prove to be very valuable [39]. The study also emphasises that new challenges and questions will emerge with further integration of VR and tourism. Tozsa's discusses how VR can be 
useful in public administration services. The article suggests that virtual reality mobile apps can help in the field of e-Government and the services provided through such apps have the simplest tools for navigation and a more attractive outlay than traditional e-Government websites. He believes that with future developments in VR such as $3 \mathrm{D}$, administration could have a variety of useful apps [40].

\section{Evaluation and Future Work}

Both AR and VR technologies have been applied in serval mobile apps. They have been used in different fields, for example education, transportation and tourism. Moreover, both technologies can be used amongst those with declining cognitive ability such as the elderly. As both technologies have proven that they can be used successfully in different fields by a various group of people, our future work will involve developing a fitness mobile apps that include the use of both AR and VR technologies as a motivational tool. The app will be designed for obese individuals to help them be motivated and lose weight to have a healthy lifestyle. The app will also consider the four main motivational features from the recent survey.

\section{Conclusion}

The literature review shows that obesity is a major problem all over the world. Obesity is defined as excessive fat in the human body. The percentage of people suffering from obesity is increased to around $15 \%$. Obesity is one of the reasons for several chronic diseases such as diabetes. Several experts believe that obesity can be fought and stopped by engaging obese individuals to perform in physical activates. However, it is hard to motivate or keep obese individuals motivated to perform physical activates for losing weight to have a better lifestyle. Yet, the majority of experts concluded that behaviour intervention could be the solution for changing behaviour. The use of fitness mobile apps is becoming popular around the world as $16 \%$ of smartphones owners use fitness and health apps. Several experts claim that fitness behaviour interventions can be gained via using mobile fitness apps especially for those people who are suffering from obesity.

Mobile fitness apps have unique features that play an important role in order to motivate or keep obese individuals to do physical activates. According to results from a recent study there are four key features helps to motivate obese individuals. These features are 1) goal settings; 2) monitoring, tracking and feedback; 3) reminders and alerts; 4) reward or gamification. However, there are more new technologies (AR and VR) that become popular among mobile app users and can be applied to help obese individuals to lose weight.

This study aims to investigate on the benefit of using both AR and VR in mobile apps. A systematic review of the most recent researches and articles that studied the use of AG and VR in mobile apps has been done. We found that AR and 
VR have played a major role to enable a better use of mobile devices and apps. They have been used in a verity of felids in mobile apps, for example, education, transportation and tourism. Moreover, both technologies are used by users with a declining cognitive ability such as the elderly. These results have encouraged us to consider applying both AR and VR when we start developing a new mobile fitness app. Our assumption is that as both technologies have advantages in other felids, they can have a positive effect on the fitness felid. The app will be designed and developed specifically for people who are suffering from obesity and want to be motivated to lose weight and have a better lifestyle.

\section{References}

1. SIMOPOUlOS, A. P., and VAN ITALLIE, T. B. 1984. "Body Weight, Health, and Longevity," Annals of internal medicine (100:2), pp. 285-295.

2. Organization, W. H. 2016. "Obesity and Overweight." Retrieved 2 October, 2016, from http://www.who.int/mediacentre/factsheets/fs311/en/

3. Fontaine, K. R., Redden, D. T., Wang, C., Westfall, A. O., and Allison, D. B. 2003. "Years of Life Lost Due to Obesity," Jama (289:2), pp. 187-193.

4. Calle, E. E., Thun, M. J., Petrelli, J. M., Rodriguez, C., and Heath Jr, C. W. 1999. "Body-Mass Index and Mortality in a Prospective Cohort of Us Adults," New England Journal of Medicine (341:15), pp. 1097-1105.

5. Summerbell, C., Waters, E., Edmunds, L., Kelly, S., Brown, T., and Campbell, K. 2005. "Interventions for Preventing Obesity in Children (Review)," Cochrane library (3), pp. 1-71.

6. Saris, W., Blair, S., Van Baak, M., Eaton, S., Davies, P., Di Pietro, L., Fogelholm, M., Rissanen, A., Schoeller, D., and Swinburn, B. 2003. "How Much Physical Activity Is Enough to Prevent Unhealthy Weight Gain? Outcome of the Iaso 1st Stock Conference and Consensus Statement," Obesity reviews (4:2), pp. 101-114.

7. Anderson, J. L., Antman, E. M., Bailey, S. R., Bates, E. R., Blankenship, J. C., Casey Jr, D. E., Green, L. A., Hochman, J. S., Jacobs, A. K., and Krumholz, H. M. 2009. "Aha Scientific Statement," Circulation (120), pp. 2271-2306.

8. Hill, J. O., and Wyatt, H. R. 2005. "Role of Physical Activity in Preventing and Treating Obesity," Journal of Applied Physiology (99:2), pp. 765-770.

9. Foster, G. D., Makris, A. P., and Bailer, B. A. 2005. "Behavioral Treatment of Obesity," The American journal of clinical nutrition (82:1), pp. 230S-235S.

10. Wadden, T. A., and Stunkard, A. J. 2002. Handbook of Obesity Treatment. Guilford Press.

11. Statista. (2014). Facts and statistics on Wearable Technology, https://www.statista.com/topics/1556/wearable-technology/

12. Pai, A. 2014, Nielsen: 46 million people used fitness apps in January, http://www.mobihealthnews.com/32183/nielsen-46-million-people-used-fitness-appsin-january

13. Statista 2016, Share of internet users who use health and fitness apps every month as of 3rd quarter 2015, https://www.statista.com/statistics/502195/health-and-fitnessapp-access/

14. Khalaf, S. 2014, Health and Fitness Apps Finally Take Off, Fueled by Fitness Fanatics, http://flurrymobile.tumblr.com/post/115192181465/health-and-fitness-appsfinally-take-off-fueled 
15. M. Essany. (2013). Mobile Health Care Apps Growing Fast in Numbe, http://mhealthwatch.com/mobile-health-care-apps-growing-fast-in-number-20052/

16. Fogg, B. J. 2002. "Persuasive Technology: Using Computers to Change What We Think and Do," Ubiquity (2002:December), p. 5.

17. Alturki, R. M., and Gay, V. 2016. "A Systematic Review on What Features Should Be Supported by Fitness Apps and Wearables to Help Users Overcome Obesity," International Journal of Research in Engineering and Technology (05: 09).

18. Smith, C. 2017, 80 Incredible Pokemon Go Statistics and Facts (April 2017), http://expandedramblings.com/index.php/pokemon-go-statistics/

19. Carmigniani, J., Furht, B., Anisetti, M., Ceravolo, P., Damiani, E., and Ivkovic, M. 2011. "Augmented Reality Technologies, Systems and Applications," Multimedia Tools and Applications (51:1), pp. 341-377.

20. Azuma, R., Baillot, Y., Behringer, R., Feiner, S., Julier, S., and MacIntyre, B. 2001. "Recent Advances in Augmented Reality," Computer Graphics and Applications, IEEE (21:6), pp. 34-47.

21. Milgram, P., and Kishino, F. 1994. "A Taxonomy of Mixed Reality Visual Displays," IEICE TRANSACTIONS on Information and Systems (77:12), pp. 1321-1329.

22. Nazri, N. I. A. M., and Rambli, D. R. A. 2014. "Current Limitations and Opportunities in Mobile Augmented Reality Applications," Computer and Information Sciences (ICCOINS), 2014 International Conference on: IEEE, pp. 1-4.

23. Adhani, N. I., and Awang, R. D. R. 2012. "A Survey of Mobile Augmented Reality Applications," 1st International Conference on Future Trends in Computing and Communication Technologies: Citeseer, pp. 89-96.

24. Rohs, M., and Gfeller, B. 2004. Using Camera-Equipped Mobile Phones for Interacting with Real-World Objects. na.

25. Höllerer, T., and Feiner, S. 2004. "Mobile Augmented Reality," Telegeoinformatics: Location-Based Computing and Services. Taylor and Francis Books Ltd., London, $U K(21)$.

26. Leung, R., Findlater, L., McGrenere, J., Graf, P., and Yang, J. 2010. "Multi-Layered Interfaces to Improve Older Adults' Initial Learnability of Mobile Applications," ACM Transactions on Accessible Computing (TACCESS) (3:1), p. 1.

27. Zhou, S., Chen, Z., Liu, X., and Tang, H. 2011. "An "Elder Mode" of New Generation Phone Using Augment Reality," Procedia Environmental Sciences (10), pp. 936-942.

28. Kim, S., and Dey, A. K. 2009. "Simulated Augmented Reality Windshield Display as a Cognitive Mapping Aid for Elder Driver Navigation," Proceedings of the SIGCHI Conference on Human Factors in Computing Systems: ACM, pp. 133-142.

29. de la Nube Aguirre Brito, C. 2015. "Augmented Reality Applied in Tourism Mobile Applications," eDemocracy \& eGovernment (ICEDEG), 2015 Second International Conference on: IEEE, pp. 120-125.

30. Hahn, J. 2012. "Mobile Augmented Reality Applications for Library Services," New library world (113:9/10), pp. 429-438.

31. Burdea, G. C., and Coiffet, P. 2003. Virtual Reality Technology. John Wiley \& Sons.

32. Weinbaum, S. G. 2015. Pygmalion's Spectacles. Booklassic.

33. Jeremy Norman's 2017, Ivan Sutherland and Bob Sproull Create the First Virtual Reality Head Mounted Display System,

http://www.historyofinformation.com/expanded.php?id=1087

34. Lippman, A. 1978. "The Aspen Movie Map," MIT ARPA.

35. Lardinois, F. 2010, Google Street View in 3D: More Than Just an April Fool's Joke, http://readwrite.com/2010/04/06/google_street_view_in_3d_here_to_stay/ 
36. Virvou, M., and Katsionis, G. 2008. "On the Usability and Likeability of Virtual Reality Games for Education: The Case of Vr-Engage," Computers \& Education (50:1), pp. 154-178.

37. Hürst, W., Beurskens, J., and van Laar, M. 2013. "An Experimentation Environment for Mobile 3d and Virtual Reality," Proceedings of the 15th international conference on Human-computer interaction with mobile devices and services: ACM, pp. 444447.

38. Gillman, A. S., and Bryan, A. D. 2015. "Effects of Performance Versus Game-Based Mobile Applications on Response to Exercise," Annals of Behavioral Medicine), pp. $1-6$.

39. Guttentag, D. A. 2010. "Virtual Reality: Applications and Implications for Tourism," Tourism Management (31:5), pp. 637-651.

40. Tozsa, I. 2013. "Virtual Reality and Public Administration," Transylvanian Review of Administrative Sciences (9:38), pp. 202-212. 